\title{
An Overview of the Latest Graphene-Based Sensors for Glucose Detection: the Effects of Graphene Defects
}

\author{
Marilena Carbone, ${ }^{*[\mathrm{a}]}$ Lo Gorton, ${ }^{[\mathrm{b}]}$ and Riccarda Antiochia*[c]
}

\begin{abstract}
In this review, we analyze several types of graphene-based sensors for glucose detection with respect to their preparation, properties and efficiency in electrochemical processes. Graphene may display different types of defects, which play a role in the electron transfer processes. Oxygenated groups on the edges of graphene planes reduce the graphene in-plane conductivity, but
\end{abstract}

may enhance the heterogeneous electron/proton transfer constant. Other positive effects of defects are related to the shortening of the distance between active centers and electrodes upon enzyme or protein immobilization. However, though by different mechanisms, all types of graphene enhance the electrochemical response at the electrode.

Keywords: Graphene-based sensors $\cdot$ Glucose detection $\cdot$ Defects $\cdot$ Heterogeneous electron/proton transfer constant

\section{Introduction}

Graphene has unique mechanical and transport properties that stimulated extensive basic studies as well as numerous applications in many fields. In recent electrochemistry studies graphene is often employed for modifying electrodes in order to achieve improved performances.

It is defined by IUPAC as "A single carbon layer of graphite structure, describing its nature by analogy to a polycyclic aromatic hydrocarbon of quasi-infinite size" [1]. This particular structure is a zero-gap semiconductor with a conical band structure and an excellent in-plane conductivity [2]. Scaling down to the real world, graphene samples experience finite dimensions, morphological defects such as dislocations, edge and edge-like defects, five, seven or eight-membered rings in the honeycomb of hexagons, holes or wiggles of the plane. Graphene sheets tend to form agglomerates or even tend to restack through $\pi-\pi$ and van der Waals interactions, unless properly separated [3].

Preparation methods imprint specific graphene defects. The two main synthesis methods routinely used for bulk preparations are chemical vapor deposition (CVD) growth and graphite exfoliation. CVD may be performed on $\mathrm{Cu}$ or $\mathrm{Ni}$ substrates and yields a single-layered graphene, which, however, needs to be detached from the substrate before using it. The dissolution process is a critical point where morphological defects may be introduced.

There are a few graphite exfoliation methods for graphene preparation, which all have in common the oxidation step [4-7]. They may use different oxidizing agents, different temperature as well as sonication conditions. Depending on the specific conditions, the product may be either graphitic or graphene oxide, a general definition for alcohol, ether, epoxy, aldehyde and carboxylic groups bonded to the graphitic/graphene structures.
Graphene oxide may be reduced chemically, thermally or electrochemically [8] and the product is then defined Reduced Graphene Oxide (RGO). Compared to graphene produced by CVD, it has smaller sheet dimensions and often residual oxide and/or nitrogen groups.

Oxidation/reduction procedures may be applied to a substrate of carbon nanotubes, instead of graphite. The consequent unzipping of the nanotubes produces nanoribbons with a variable degree of oxidation as well as number of layers, similarly to graphene oxide.

Everything that alters the perfect infinite single layer structure of graphene is often referred to as a defect.

Typically, TEM [9], Raman [10-12] and XPS [12,13] techniques are used to determine the number of layers obtained, their degree of oxidation/nitridation and the extension of morphological defects.

The investigation of direct electron transfer (DET) between redox enzymes and electrodes is a key process in the development of electroanalytical applications and bioelectrocatalytic devices [14-17]. In recent years a lot of reagentless biosensors and bioreactors have been proposed that employ DET by immobilizing an enzyme on a proper conductive electrode material. The enhancement of the performances, however, may be related to the in-

\footnotetext{
[a] M. Carbone

Department of Chemical Science and Technologies,

University of Rome Tor Vergata

Via della Ricerca Scientifica, 1-00133 Roma Italy

*e-mail:marilena.carbone@roma2.infn.it

[b] L. Gorton

Department of Analytical Chemistry/Biochemistry and

Structural Biology, Lund University

P. O.Box 124, SE-221 00 Lund, Sweden

[c] R. Antiochia

Department of Chemistry and Drug Technologies, Sapienza

University of Rome

Piazzale Aldo Moro, 5-00185 Roma Italy

*e-mail: riccarda.antiochia@uniroma1.it
} 
trinsic properties of graphene as well as to the presence of defects. It has been suggested by Pumera [18] that the presence of oxygen containing groups on the graphene surface may enhance the heterogeneous electron and charge transfer rate. The oxygen-containing species are located mostly on the edges of the graphene sheets hence the size of the graphene sheet also plays a role.

\begin{abstract}
Marilena Carbone was born in Foggia (Italy) in 1969 and obtained her MSc in Chemistry in 1992, followed by a $\mathrm{PhD}$ with honors in Materials Science in 1995. For a year she held a post-doc on computational chemistry in Sweden. Since 1996 she became a researcher in Inorganic Chemistry at the University of Rome Tor Vergata. Her research interests are materials with applications in electrochemistry, molecular biology and surface science. She has been a guest scientist at

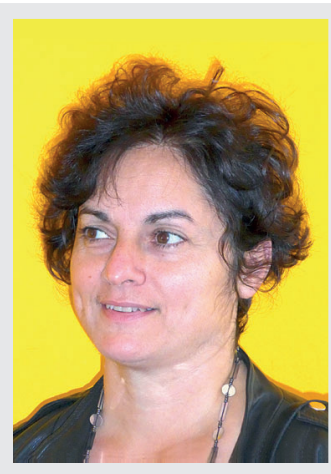
the Laboratoire de Photophysique Molèculaire in Orsay, France in 1999 and 2000, and Elettra synchrotron facility Trieste, Italy in 2002 and 2003.
\end{abstract}

Lo Gorton was born in 1949 in Stockholm (Sweden). He received his $\mathrm{PhD}$ in analytical chemistry from Lund University in 1981. After that, he held various positions at the same university until 1997 when he became full professor and chair in analytical chemistry. He has been working on various aspects on the use of primarily enzymes and bacteria in analytical chemistry/bioelectrochemistry. His current main interest is studies on electron-transfer reactions between

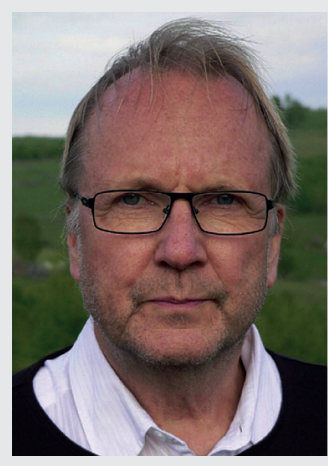
redox enzymes/bacterial cells and electrode surfaces. He became "Professor Honoris Causa of the University of Bucharest" in 2000, "Visiting Honorary Professor of the University of Xianfang City" in 2010, "Fellow of the International Society of Electrochemistry" in 2012. He was awarded "The International DropSens Award" in 2012 and "The Katzumi Niki prize in Bioelectrochemistry" awarded by Division 2 (Bioelectrochemical division) of the International Society of Electrochemistry in 2014.

Riccarda Antiochia obtained her MSc degree in Chemistry in 1992 and a MSc degree in Pharmacy in 2009. In 1996 she received a PhD in Analytical Chemistry and since 2000 she is a researcher at La Sapienza University of Rome. Her fields of research are biosensors, studies on electrode kinetics, chemically modified electrodes, nanostructured electrode materials, liquid chromatography and their use for determination and analysis of analytes of food and biomedical interest.
Furthermore, residual oxygen on graphene substrate is crucial in further enzyme immobilization. When produced by CVD, graphene is deposited on metal substrates. The use of graphene sheet is, then, conditioned by the etching of the substrate, a procedure which may introduce morphological defects in the structure, but also leave contaminants, typically $\mathrm{Fe}$ from $\mathrm{FeCl}_{3}$ or $\mathrm{Fe}(\mathrm{NO})_{3}$ etching solutions, on the graphene surface [19]. Such defects may be functional to the nucleation of metals in the synthesis of composite materials, but definitively Fe contamination affects the electrochemical behavior.

Even when single carbon layers are obtained, when deposited on the electrode, they stack up together to yield a multilayer, with a consequent variation of the electrocatalytic properties $[20,21]$. Polymers and ionic liquids may be employed in the assembling of graphene-based electrodes in order to keep the graphene sheets separated, but they definitively intervene in the electrochemical transfer process, for instance by forming a diffusion barrier for the analytes, reducing the active area of the working electrode/biosensor [22].

In general, the way of producing graphene (hence its structure) as well as the way of assembling graphenebased electrodes influence the electrochemical performances.

Although graphene-based sensors are used for a large numbers of targets [23-29], in the following sections an analytical comparison of the electrochemical performances of various graphene-based biosensors for glucose detection will be reported. Some non-enzymatic sensors will also be analyzed. A summary of the properties are given in Tables 1 and 2. For all the electrochemical systems, indications are given on the type of graphene used, the electrode assembly and, whenever possible, the techniques employed in the determination of the graphene properties. The electrochemical properties of the relative biosensors such as $L O D$, sensitivity, stability are also reported, and a critical correlation is made.

\section{Graphene-Based Enzymatic Glucose Biosensors}

In this section, we analyze 19 different graphene-based glucose enzymatic biosensors. A straightforward comparison of their performances is not possible, because the type of graphene used for the modified electrodes and the assembling methods change in each preparation.

However, a case-by-case assessment can be made on the defects of the graphene and their probable role either in the electrode construction and/or on the electrochemical performance.

A subdivision of the electrodes is made, depending on the type assembling or graphene treatment or preparation. Therefore, five subsections are made whether i) polymers and/or ionic liquids are employed, ii) direct drop casting is employed iii) metal/graphene composites are made, iv) chemical doping is used, v) graphene is obtained by CVD. 
Table 1. Comparison of the structural properties and electrochemical performances of various graphene-based enzymatic biosensors for glucose detection. Acronyms of the techniques used are: SEM: scanning electron microscopy, TEM: transmission electron microscopy, HRTEM: high resolution transmission electron microscopy, XPS: X-ray photoelectron spectroscopy, IR: infra red spectroscopy, XRD: X-ray diffraction, AFM: atomic force microscopy. Abbreviations used in connection to "type of graphene": RGO: reduced graphene oxide, GO: graphene oxide, PFIL: polyethylenimine-functionalized ionic liquid, PIL: polymeric ionic liquid, PEI: polyethyleneimine, PAA: pyrene-polyacrylic acid, Ppy: polypyrrole, PANI: polyaniline, PAMAM: poly(amido amine).

\begin{tabular}{|c|c|c|c|c|c|c|c|c|c|}
\hline $\begin{array}{l}\text { Graphene } \\
\text { treatments }\end{array}$ & $\begin{array}{l}\text { Type of } \\
\text { electrode }\end{array}$ & Type of graphene & $\begin{array}{l}\text { Functional } \\
\text { groups }\end{array}$ & $\begin{array}{l}\text { Structure de- } \\
\text { tection tech- } \\
\text { nique }\end{array}$ & $\begin{array}{l}\text { Linear } \\
\text { range } \\
(\mathrm{mM})\end{array}$ & $\begin{array}{l}\angle O D \\
(\mu \mathrm{M})\end{array}$ & $\begin{array}{l}\text { Sensitivity } \\
\left(\mu \mathrm{A} \mathrm{cm}^{-2}\right. \\
\left.\mathrm{mM}^{-1}\right)\end{array}$ & Stability & Reference \\
\hline Polymer/IL & $\mathrm{GC}$ & RGO/PFIL & $\begin{array}{l}\text { Residual } \\
\text { Oxygen Ni- } \\
\text { trogen }\end{array}$ & TEM-XPS & $2-14$ & - & - & $\begin{array}{l}4.9 \% \text { decrea- } \\
\text { seafter } \\
1 \text { week }\end{array}$ & {$[30]$} \\
\hline Polymer/IL & $\mathrm{Pt}$ & RGO/PIL & Carboxyl & AFM, TEM & $\begin{array}{l}1 \times 10^{-3}- \\
100\end{array}$ & 1 & $\begin{array}{l}5.58 \mu \mathrm{A} / \\
\text { decade }\end{array}$ & - & {$[32]$} \\
\hline Polymer & GC & GO/PEI/PAA & No clear & Raman, AFM & - & 0.168 & 0.26 & - & [33] \\
\hline Polymer & GC & graphene-chitosan & $\begin{array}{l}\text { Hydroxyl, } \\
\text { carboxyl }\end{array}$ & SEM & $0.08-12$ & 20 & 37.93 & $\begin{array}{l}5 \% \text { decrease } \\
\text { after } 1 \text { week }\end{array}$ & [34] \\
\hline $\begin{array}{l}\text { Direct } \\
\text { drop cast- } \\
\text { ing }\end{array}$ & GC & RGO & $\begin{array}{l}\text { Hydroxyl, } \\
\text { carbonyl }\end{array}$ & IR, XRD & $0.1-27$ & - & 1.85 & $\begin{array}{l}7 \% \text { decrease } \\
\text { after } 3 \text { weeks }\end{array}$ & [37] \\
\hline Polymer & GC & Ppy/graphene & Not clear & $\begin{array}{l}\text { RAMAN, } \\
\text { TEM, SAM, } \\
\text { IR }\end{array}$ & $\begin{array}{l}2 \times 10^{-3}- \\
4 \times 10^{-4}\end{array}$ & 3 & - & - & [39] \\
\hline $\begin{array}{l}\text { Direct } \\
\text { Drop Cast- } \\
\text { ing }\end{array}$ & GC & RGO & Oxygen & XPS, AFM & $0.01-10$ & 2 & 20.21 & - & {$[38]$} \\
\hline $\begin{array}{l}\text { Direct } \\
\text { Drop Cast- } \\
\text { ing }\end{array}$ & GC & $\begin{array}{l}\text { reduced carboxyl } \\
\text { graphene }\end{array}$ & $\begin{array}{l}\text { Carboxyl, } \\
\text { epoxy, hy- } \\
\text { droxyl }\end{array}$ & XPS. SEM & $2-18$ & 20 & 7 & $\begin{array}{l}4.6 \text { decrease } \\
\text { after } 2 \text { weeks }\end{array}$ & [40] \\
\hline $\begin{array}{l}\text { Chemical } \\
\text { Doping }\end{array}$ & GC & $\mathrm{N}$-doped graphene & Oxygen & $\begin{array}{l}\text { XPS, TEM, } \\
\text { AFM }\end{array}$ & $0.1-1.1$ & 10 & - & - & [49] \\
\hline $\begin{array}{l}\text { Composite/ } \\
\text { Metal }\end{array}$ & $\mathrm{Au}$ & $\begin{array}{l}\text { graphene/AuNPs/ } \\
\text { chitosan }\end{array}$ & Not clear & XPS, TEM & $2-10$ & 180 & - & $\begin{array}{l}4.6 \% \text { de- } \\
\text { crease after } \\
15 \text { days }\end{array}$ & [41] \\
\hline $\begin{array}{l}\text { Composite/ } \\
\text { Metal }\end{array}$ & GC & $\begin{array}{l}\text { Nafion/graphene/ } \\
\text { AuNPs (hydroqui- } \\
\text { none) }\end{array}$ & Not clear & XRD, TEM & $0.015-5.8$ & 5 & - & $\begin{array}{l}10 \% \text { decraese } \\
\text { after } 3 \text { weeks }\end{array}$ & [42] \\
\hline $\begin{array}{l}\text { Composite/ } \\
\text { Metal }\end{array}$ & GC & graphene/CdS & Oxygen & TEM, IR & $2-16$ & 700 & - & $\begin{array}{l}7 \% \text { decrease } \\
\text { after } 30 \text { days }\end{array}$ & [45] \\
\hline $\begin{array}{l}\text { Composite/ } \\
\text { Metal }\end{array}$ & GC & $\begin{array}{l}\text { PtNPs/graphene } \\
\text { sheets/chitosan }\end{array}$ & $\begin{array}{l}\text { Hydroxyl/ } \\
\text { epoxy groups }\end{array}$ & TEM & $\begin{array}{l}\text { sub } \mu \mathrm{M}- \\
5\end{array}$ & 0.6 & - & $\begin{array}{l}14 \% \text { decrease } \\
\text { after } 1 \text { week }\end{array}$ & [46] \\
\hline $\begin{array}{l}\text { Composite/ } \\
\text { Metal }\end{array}$ & $\mathrm{Pt} / \mathrm{Ir}$ & GO/Pt-black & All & SEM & $1 \times 10^{-3}-2$ & 1 & 744 & $\begin{array}{l}9 \% \text { decrease } \\
\text { after } 1 \text { week }\end{array}$ & [47] \\
\hline $\begin{array}{l}\text { Composite/ } \\
\text { Metal }\end{array}$ & GC & $\mathrm{GO} / \mathrm{TiO}_{2}$ & Not clear & SEM, XPS. & $0-8$ & - & 6.20 & - & [48] \\
\hline CVD & $\mathrm{GC}$ & $\begin{array}{l}\text { single-layer gra- } \\
\text { phene/AuNPs }\end{array}$ & None & Raman, SEM & $0.01-0.37$ & 4 & - & - & {$[50]$} \\
\hline CVD & SP & $\begin{array}{l}\text { graphene } / \mathrm{Fe}_{3} \mathrm{O}_{4} / \\
\text { PANI }\end{array}$ & None & AFM, SEM & $2.9-23$ & - & 47 & - & [51] \\
\hline $\begin{array}{l}\text { Composite/ } \\
\text { Metal }\end{array}$ & GC & $\mathrm{Co}_{3} \mathrm{O}_{4} \mathrm{NPs}$-graphene & Not clear & SEM, XRD & $0.5-16.5$ & 50 & 13.52 & $\begin{array}{l}11 \% \text { decrease } \\
\text { after } 9 \text { days }\end{array}$ & [58] \\
\hline $\begin{array}{l}\text { Direct } \\
\text { drop cast- } \\
\text { ing }\end{array}$ & GC & graphene & None & $\begin{array}{l}\text { AFM, FT-IR, } \\
\text { IR, CD }\end{array}$ & $0.1-10$ & 10 & 110 & - & [59] \\
\hline $\begin{array}{l}\text { Composite/ } \\
\text { Metal }\end{array}$ & GC & RGO-PAMAM-Ag & $\begin{array}{l}\text { Carboxyl, } \\
\text { aryl }\end{array}$ & $\begin{array}{l}\text { Raman, TEM, } \\
\text { HRTEM }\end{array}$ & $\begin{array}{l}0.032- \\
1.89\end{array}$ & 4.5 & 75.72 & - & [60] \\
\hline
\end{tabular}

\section{Polymers and/or Ionic Liquids Employment}

Shan et al. [30] reported on a graphene-based biosensor modified with glucose oxidase (GOD) and polyethylenimine-functionalized ionic liquid (PFIL) with a high electrocatalysis of $\mathrm{O}_{2}$ and $\mathrm{H}_{2} \mathrm{O}_{2}$. It shows a wide linear glu- cose response (2-14 $\mathrm{mM})$, good reproducibility and high stability ( $4.9 \%$ current increase after 1 week).

The preparation of the electrode required several steps. Graphite oxide was synthesized according to the Kovtyukhova [31] modified Hummers method and, then, protected by polyvinylpyrrolidone (PVP). At this stage a chemi- 
Table 2. Comparison of the structural properties and electrochemical performances of various graphene-based non-enzymatic biosensors for glucose detection. Acronyms of the techniques used are: SEM: scanning electron microscopy, TEM: transmission electron microscopy, XPS: X-ray photoelectron spectroscopy, IR: infra red spectroscopy, XRD: X-ray diffraction, AFM: atomic force microscopy, EDX: energy dispersive X-ray spectroscopy. Abbreviations used in connection to "type of graphene": PtNFs: platinum nanoflowers, PDDA: poly(diallyldimethylammonium chloride).

\begin{tabular}{|c|c|c|c|c|c|c|c|c|c|}
\hline $\begin{array}{l}\text { Graphene } \\
\text { treatments }\end{array}$ & $\begin{array}{l}\text { Type of } \\
\text { electrode }\end{array}$ & $\begin{array}{l}\text { Type of gra- } \\
\text { phene }\end{array}$ & $\begin{array}{l}\text { Functional } \\
\text { groups }\end{array}$ & $\begin{array}{l}\text { Structure detec- } \\
\text { tion technique }\end{array}$ & $\begin{array}{l}\text { Linear } \\
\text { range } \\
(\mathrm{mM})\end{array}$ & $\begin{array}{l}\angle O D \\
(\mu \mathrm{M})\end{array}$ & $\begin{array}{l}\text { Sensitivity } \\
\left(\mu \mathrm{Acm} \mathrm{cm}^{-2} \mathrm{mM}^{-1}\right)\end{array}$ & Stability & Reference \\
\hline $\begin{array}{l}\text { Composite/ } \\
\text { Metal }\end{array}$ & GC & PtNFs-GO & Not clear & TEM & $0.002-20.3$ & 2 & - & $\begin{array}{l}26 \% \text { decrease } \\
\text { after } 2 \text { weeks }\end{array}$ & [52] \\
\hline $\begin{array}{l}\text { Composite/ } \\
\text { Metal }\end{array}$ & GC & PdNPs/RGO & $\begin{array}{l}\text { Traces of } \\
\text { hydroxyl }\end{array}$ & $\begin{array}{l}\text { TEM, IR, } \\
\text { AFM,SEM }\end{array}$ & $0.01-5.00$ & 1 & - & $\begin{array}{l}2 \% \text { decrease } \\
\text { after } 35 \text { days }\end{array}$ & [53] \\
\hline $\begin{array}{l}\text { Composite/ } \\
\text { Metal }\end{array}$ & GC & $\begin{array}{l}\text { graphene/ } \\
\text { Nafion/CuO }\end{array}$ & Not Clear & $\begin{array}{l}\text { TEM, XRD, } \\
\text { Raman }\end{array}$ & $0.002-0.06$ & 0.29 & 1480 & $\begin{array}{l}8 \% \text { decrease } \\
\text { after } 30 \text { days }\end{array}$ & [54] \\
\hline $\begin{array}{l}\text { Composite/ } \\
\text { Metal }\end{array}$ & GC & $\begin{array}{l}\mathrm{Cu} / \mathrm{PANI} / \\
\mathrm{RGO}\end{array}$ & Not clear & $\begin{array}{l}\text { SEM, XRD, } \\
\text { FTIR }\end{array}$ & $0.01-9.66$ & 1.34 & 603.59 & - & [55] \\
\hline $\begin{array}{l}\text { Chemical } \\
\text { doping }\end{array}$ & GC & $\begin{array}{l}\mathrm{Co} / \mathrm{N} \text {-doped/ } \\
\mathrm{PDDA} / \mathrm{RGO}\end{array}$ & Not clear & $\begin{array}{l}\text { SEM, TEM, } \\
\text { XRD, XPS }\end{array}$ & $0.01-4.75$ & 6.93 & 1.167 & - & [56] \\
\hline CVD & - & $\begin{array}{l}\text { graphene- } \\
\mathrm{Co}_{3} \mathrm{O}_{4}\end{array}$ & Not clear & $\begin{array}{l}\text { SEM, XRD, } \\
\text { Raman }\end{array}$ & $0.01-0.08$ & 0.025 & 33900 & - & [57] \\
\hline $\begin{array}{l}\text { Composite/ } \\
\text { Metal }\end{array}$ & GC & $\begin{array}{l}\mathrm{Ni}-\mathrm{Co} \mathrm{NSs} / \\
\mathrm{RGO}\end{array}$ & Not clear & SEM, XRD & $0.01-2.65$ & 3.79 & 1773.61 & $\begin{array}{l}3.8 \% \text { decrease } \\
\text { after } 45 \text { days }\end{array}$ & [61] \\
\hline $\begin{array}{l}\text { Composite/ } \\
\text { Metal }\end{array}$ & GC & $\begin{array}{l}\mathrm{Cu}-\mathrm{Co} \text { NSs/ } \\
\text { RGO/Chitosan }\end{array}$ & Not clear & SEM, EDX & $0.015-6.96$ & 10 & 1921 & - & [62] \\
\hline $\begin{array}{l}\text { Composite/ } \\
\text { Metal }\end{array}$ & GC & $\begin{array}{l}\text { Ni/Quercitin/ } \\
\text { graphene }\end{array}$ & Not clear & - & $0.003-0.9$ & 0.5 & 2671.43 & $\begin{array}{l}7.3 \% \text { decrease } \\
\text { after } 20 \text { days }\end{array}$ & [63] \\
\hline
\end{tabular}

cal reduction with hydrazine and ammonia was carried out. The PVP-protected graphene and PFIL solutions are mixed and dropped on a GC electrode. Finally, the electrode is soaked in GOD solution.

The PVP-graphene dispersed in PFIL aqueous solution has good film stability, high solubility, high ionic conductivity for enhanced electrochemical performance. These properties may be related to the specific interaction of the ionic liquid with residual oxidation/nitridation groups.

In the paper, an XPS spectrum is reported of pure graphene, i.e. reduced graphite oxide without PVP stabilizing agent, and it clearly shows that traces of both the oxidation and reduction procedure are present. Though to a smaller extent compared to starting graphite/graphene oxide, higher binding energy components of $\mathrm{C} 1 \mathrm{~s}$ peak are present, showing the residual oxidation and nitridation of graphene. The TE micrograph shows rather wide, thin, possibly single-layered graphene areas.

Hasan et al. [32] demonstrated a novel and efficient glucose biosensor based on functionalized graphene, deposited on a needle-like Pt electrode. The assembling of the biosensor is a clear example of the role of residual oxidation groups on graphene.

Graphene is prepared by the Hummers method, followed by sonication, reduction with hydrazine and stabilization with dpolyquaternium (95\% molar imidazolium chloride, $5 \%$ molar vinylimidazole). Dpoly is a positively charged polymeric ionic liquid (PIL) and the interaction with the graphene sheets is possible, because of the presence of residual negatively charged groups on the surface. The quality of the RGO is probed by AFM and low resolution TEM and shows, indeed, the achievement of a single sheet graphene. Subsequent GOD immobilization occurs through two mechanisms: a direct binding between the residual carboxylic acid groups of the reduced graphene oxide (RGO) and the amino-groups of GOD, and the electrostatic interactions between the PIL and GOD.

The resulting glucose biosensor showed a wide linear range up to $100 \mathrm{mM}$ glucose, a detection limit of $1 \mu \mathrm{M}$ and a sensitivity of $5.59 \mu \mathrm{A} /$ decade.

Zeng et al. [33] build up a glucose biosensor by modifying electrodes with a sort of polymer cage or a $3 \mathrm{D}$ organization for the graphene sheets. This is achieved by modifying reduced graphene oxide sheets, with pyrene-polyacrylic acid (PAA) and then by alternate deposition of graphene-PAA and polyethyleneimine (PEI). The synthesis of the RGO is performed with the widely used Hummers method and by subsequent sonication and reduction with hydrazine. However, in this as in many other cases, no compositional analysis is performed after the reduction step and it is not clear whether the reduction is complete. Raman spectra are reported in a range between 1000 and $2000 \mathrm{~cm}^{-1}$ and interpreted in terms of domain size. AF microscopies are compatible with a single-layered graphene. The interaction between RGO and PAA occurs through $\pi-\pi$ stacking of the aromatic pyrene rings and the graphene structure. Though increasing the dispersion capability, such an interaction is bound to reduce the graphene conductivity. The GC modified electrode is, then, built by electrostatic interaction of positively charged graphene-PAA and negatively charged PEI.

The electrocatalytic activity is evaluated by probing the detection of $\mathrm{H}_{2} \mathrm{O}_{2}$. Compared to the bare $\mathrm{GC}$ electrode, the multilayer film electrode shows much higher oxida- 
tion and reduction currents, a lower oxidation potential and a much higher reduction potential. The electrocatalytic activity depends on the number of bilayers on the electrode. The oxidation current (at $1 \mathrm{~V}$ ) vs. the bilayer number shows a fast increase up to 2 bilayers and much slower one from 3 to 8 bilayers.

The detection limit and sensitivity for glucose and maltose biosensors were, respectively, $0.168 \mathrm{mM}$ and $0.261 \mu \mathrm{A} \mathrm{mM}^{-1} \mathrm{~cm}^{-2}$ for glucose and $1.37 \mathrm{mM}$ and $0.00715 \mu \mathrm{A} \mathrm{mM}^{-1} \mathrm{~cm}^{-2}$.

Kang et al. [34] studied the direct electron transfer (DET) of a GOD graphene-chitosan nanocomposite based biosensor. However, within the preparation section, the carbon-based material is indicated as graphene functionalized with hydroxyl and carboxylic groups, though no composition characterization is reported. Chitosan is subsequently used to disperse graphene and form a nanocomposite film on the GC electrode.

It was found that the nanocomposite film can provide a better environment for GOD. The realized GOD-graphene-chitosan biosensor exhibited excellent sensitivity $\left(37.93 \mu \mathrm{A} \mathrm{mM}^{-1} \mathrm{~cm}^{-2}\right)$, a wide linear range $(0.08-12 \mathrm{mM})$, a detection limit of $0.02 \mathrm{mM}$ and an excellent stability (the biosensor retained almost $95 \%$ of its initial response stored at $4{ }^{\circ} \mathrm{C}$ after 1 week). The electron-transfer rate constant of the GOD in the modified film was estimated using Lanviron's model [35] and it was found higher $\left(2.83 \pm 018 \mathrm{~s}^{-1}\right)$ than on MWCNTs-chitosan $\left(1.08 \mathrm{~s}^{-1}\right)$ [36] The authors claimed DET between GOD and the electrode but, as in many other papers on GOD claiming DET, it is most probable that what is interpreted as DET is the electrochemistry of the non-covalently bound FAD coming out of active site and being adsorbed on the electrode surface. We, the authors of this review paper, are highly critical to all those papers claiming DET with GOD and especially carbon based electrodes. However, as the focus of this paper is not on DET between redox enzymes and electrodes, below we do not discuss whether true DET is obtained between GOD and the conducting electrode material, but rather use "DET" when referring to references claiming DET.

In general, chitosan enhances the performance of the biosensor acting as efficient graphene dispersing agent and enzyme immobilizing agent, though an excessive amount may form a diffusion barrier for the analytes, which reduces the active area of the biosensors. Also the presence of oxidation groups on graphene might play an important role. Much better results were obtained when also a metal is included in the graphene composite as reported forward in the "Composites with metals" section by $\mathrm{Wu}$ et al. [46].

A simple and easy electrochemical approach to develop a glucose biosensor based on reduced graphene and GOD has been proposed by Unnikrishnan et al. [37]. The immobilization of GOD was achieved by direct coupling, without any cross linking agent. Afterwards the graphene oxide was electrochemically reduced by performing continuous potential cycling from 0 to $-1.5 \mathrm{~V}$. The reduction process, however, is not complete and fingerprints of oxygen-containing compounds may be observed in the infrared spectrum.

Cyclic voltammetry experiments were carried out to study the "direct electron" transfer between GOD and the electrode. Glucose detection was obtained in mediator-free conditions and the biosensors showed very good catalytic activity towards glucose over a wide linear range of $0.1-27 \mathrm{mM}$ with a sensitivity of $1.85 \mu \mathrm{AmM}^{-1} \mathrm{~cm}^{-2}$. The stability of the proposed biosensor was very good as after 20 days the biosensor retained $93 \%$ of its initial response.

\subsection{Direct Drop Casting}

The performances of the electrode in [37] are very interesting if compared to those of the electrode developed by Zhou et al. [38] in 2009. They modified a GC electrode by drop casting first chemically reduced GO (which still shows the presence of residual oxygen groups in the XPS spectrum) and, then, GOD. This biosensor shows a better electrochemical performance for the detection of glucose compared with graphite/GC or GC-based bioelectrodes: a wide linear range $(0.01-10 \mathrm{mM})$, high sensitivity $\left(20.21 \mu \mathrm{AmM}^{-1} \mathrm{~cm}^{-2}\right)$ and a low detection limit $(2.00 \mu \mathrm{M})$. These parameters, however, are different from those reported by Unnikrishnan [37] for a similar biosensor, where the only apparent difference is the order of binding of the same moieties to the electrode. There may be several reasons for the different performances, the RGO/GOD ratio, the load of the electrode, but also the different preparations of graphene with the consequent different structures.

Another example of "direct electron transfer" in graphene-based electrodes for glucose detection was presented by Alwarappan et al. [39] who covalently conjugated RGO and GOD prior to deposition onto a glassy carbon electrode modified with polypyrrole (Ppy). They synthesize graphitic oxide with the Hummers method, suspended and ultrasonicated the oxide and then treated it with hydrazine hydrate. The outcome is graphene oxide, which can be directly conjugated to GOD. GO is investigated by TEM and Raman and shows a structure with a few layers. The GC electrode is dipped into a Ppy solution that can undergo electrochemical polymerization and create a transduction matrix support. Ppy has a porous structure and is capable of encapsulating the grapheneGOD assembly without altering the structure or denaturing the GOD activity. The obtained biosensor has a better performance than the non-GOD conjugated counterpart. The detection limit is $3 \mu \mathrm{M}$ and the linear range $2-40 \mu \mathrm{M}$. The enhanced performances are attributed to the covalent modification, which is expected to bring the GOD reactive center (the flavine adenine dinucleotide - FAD) closer to the surface and facilitate a possible direct electron transfer.

Graphene has been widely employed in sensors assembling because of its conduction properties. The oxidized 
form may enhance the heterogeneous electron transfer in an electrochemical process, but it suffers from a partial loss of conductivity. This may affect the performances of electrodes where direct electron transfer processes are involved. On the other hand, a lack of functional groups on the graphene sheets makes it difficult to immobilize enzymes on the graphene surface.

A sort of compromise is achieved by Liang et al. [40] who proposed a glucose biosensor with "direct electron transfer" based on electrochemically reduced carboxyl graphene (ERC-GR) modified glassy carbon electrode and self-assembly of GOD. Carboxyl graphene was purchased and XPS analysis revealed the presence also of alcohol and epoxy groups. The electrochemical reduction diminished the amount of intermediate oxidation groups but left almost all the carboxylic groups.

SEM images clearly showed that the ERCGR film has a typical crumpled and wrinkled sheet structure of graphene which provides a large rough surface for successful immobilization of GOD. The outcome is a homogeneous mushy film. Cyclic voltammetric experiments indicated a much better performance of the ERCGr/GOD, compared to the non-reduced CGr/GOD electrode. Furthermore, a highly reversible "direct electron transfer" between GOD and the ERCGr electrode is achieved. The developed glucose biosensor showed a linear response to glucose concentrations ranging from 2 to $18 \mathrm{mM}$ with a detection limit of $0.02 \mathrm{mM}$ and a sensitivity of $7 \mu \mathrm{AmM}^{-1} \mathrm{~cm}^{-2}$. The stability of the biosensor was good with a reduction of the initial current response of about $4.6 \%$ after two weeks storage at $4{ }^{\circ} \mathrm{C}$.

A novel efficient biosensing platform based on graphene sheets integrated with GOD has been proposed by $\mathrm{Wu}$ et al. [59]. The hybrid has been demonstrated to be a good electrocatalyst for the reduction of oxygen. Cyclic voltammograms experiments indicated that GOD assembled on graphene retained its native activity, showed a surface-confined process and underwent effective "DET" reaction with an apparent rate constant of $2.68 \mathrm{~s}^{-1}$. Upon glucose addition, the reduction current of dissolved oxygen electrocatalyzed by GOD decreased and the so realized glucose biosensor showed a high sensitivity of $110 \mu \mathrm{AmM}^{-1} \mathrm{~cm}^{-2}$, a wide linear range between 0.1 and $10 \mathrm{mM}$ and a low detection limit of $10 \mu \mathrm{M}$. Due to the use of a low detection potential, the glucose biosensor can exclude the interference of commonly coexisting electroactive species.

\subsection{Composites with Metals}

Metal and metal oxide nanoparticles may be co-immobilized with graphene on the electrode and/or the electrode itself may be a metal. In both cases the response of the related biosensor may change and graphene defects, again, may play a role (positive or negative) in the assembling and in the electrochemistry.

As first examples of such preparations, we report again a paper by Shan et al. [41], on graphene/AuNPs/chitosan composite film based biosensor for glucose detection. AuNPs are added because they are supposed to act as fine conducting wires or electron tunnel to promote electron exchange at the electrode/protein interface.

This biosensor is to be compared to the one reported on in [30], where the performance of a similar composite was reported, though in absence of AuNPs, but with ionic liquids. The graphitic oxide of this composite film is prepared in a similar way and is also stabilized with PVP. The chemical reduction, however, is performed with $\mathrm{NaBH}_{4}$, in presence of $\mathrm{HAuCl}_{4}$ to obtain AuNPs dispersed in the graphene layer. Chitosan was added afterwards. The electrochemical performance of the graphene/ AuNPs/chitosan composite is quite good. The film exhibits good electrocatalytic activity toward $\mathrm{H}_{2} \mathrm{O}_{2}$ and $\mathrm{O}_{2}$. With GOD, the resulting biosensor showed a wide linear range $(2-10 \mathrm{mM})$, a detection limit of $180 \mu \mathrm{M}$ and a very good stability ( $4.6 \%$ increase after 15 days). However, compared to Ref. 30, the linear range is smaller (2-10 vs. 2-14). The $L O D$ cannot be compared as it is not reported in the former case. The stability is quite good in both cases.

It is difficult to make a correlation between the structure and the electrochemical performances, because, in the latter paper Shan et al. [41] focused only on the compositional and morphological information on the AuNPs. The Au XPS spectrum is quite diagnostic, and also the dispersion of the nanoparticles is good. We do not know whether the different reduction procedure was more or less effective than the previously used one. Hence, we do not know whether it is a lack or an excess of oxygen to cause the reduced linear range. Furthermore, no ionic liquids were used, which definitively act against graphene agglomeration and re-stacking. Also this condition may be the reason for the smaller linear range.

Zhou et al. [42] constructed a novel glucose biosensor where graphene, AuNPs and GOD were co-immobilized in Nafion to modify a glassy carbon electrode. Graphene was prepared by graphite oxidation and following sulfonation [43], so that the sterical hindrance sulfonic group of the would help the exfoliation. The GS is then reduced by hydrazine and the product is probed by XRD and TEM. The outcome is a nearly TEM-transparent sheet with a diffraction pattern broadened by the loss of the $3^{\text {rd }}$ dimension, with the correct position of the peaks. Treatments-related residual groups are not probed and it is not clear whether oxygen, sulfur or nitrogen groups are still present. Graphene is, then, dispersed in Nafion, mixed with AuNPs and finally deposited on a GC electrode.

In the presence of hydroquinone as redox mediator, the biosensor showed a linear range from 0.015 to $5.8 \mathrm{mM}$, a detection limit of $5 \mu \mathrm{M}$ and long term stability ( $90 \%$ of the initial response after 3 weeks). $K_{\mathrm{M}}$, the Michaelis-Menten constant was calculated to be $4.4 \mathrm{mM}$. Such good properties have been ascribed, by the authors, to the synergistic effect of graphene-Au integration and to the good biocompatibility of the hybrid material. Other non-graphene glucose detection systems, for in- 
stance the CNT-Au-PDDA-GOD [44] reported for comparison in the same paper, show a relatively smaller linear range $(0.5-2.2 \mathrm{mM})$, but also a lower $K_{\mathrm{m}}$ $(1.76 \mathrm{mM})$. The detection limit in the latter case is not reported.

Wang et al. [45] reported the utilization of graphene$\mathrm{CdS}$ nanocomposite based biosensor for glucose. Graphene-CdS nanocomposite exhibited excellent electron transfer properties for GOD and the reason is indicated as the synergic effect of graphene sheet and CdS nanocrystals. The glucose biosensor showed a good linear range $(2-16 \mathrm{mM})$, a good detection limit $(0.7 \mathrm{mM})$ and a very long stability (the biosensor retains $93 \%$ of its initial value after 30 days of use). As for the type of graphene used, it is synthesized by the Hummers method and dispersed in water. Then, the synthesis of CdS is performed in presence of graphite oxide. The TEM of the product shows a good dispersion of the nanoparticles, in thin layers of carbon-based material, though probably not single layer. However, nothing is known on the oxidation of the final product. Subsequently, the composite was suspended in Nafion and then GOD was immobilized. The infrared spectra of the nanocomposite with GOD show a small, but significant shift of the amide II band, a sign that an amino acid bond occurred between the substrate and the enzyme. This indirectly implies that oxygen groups are still present on graphene and have, at least, a role in immobilizing the enzyme.

$\mathrm{Wu}$ et al. [46] described a new bionanocomposite film consisting of $\mathrm{Pt} /$ functional graphene sheets/chitosan for glucose detection. The graphene used in this study was made by thermal exfoliation of graphene oxide. This type of preparation yields mostly wrinkled graphene sheets functionalized with hydroxyl and epoxy groups. Afterwards the graphene oxide was dispersed in a chitosan solution and the resulting product was cast onto a glassy carbon electrode surface. The Pt nanoparticles were electrochemically deposited and GOD was immobilized. The biosensor showed one of the best detection limits $(0.6 \mu \mathrm{M})$ among the papers analyzed in this review regarding graphene-based glucose biosensors, a linear range from sub $\mu \mathrm{M}$ to $5 \mathrm{mM}$ glucose and long term stability (14\% decrease of initial response after 1 week). The good sensitivity of this biosensor could be attributed to a large surface area and to a fast electron transfer activity of functionalized graphene sheets. The highest electrocatalytic activity in the set of measurements was shown by the hybrid $\mathrm{Pt} / \mathrm{GO} /$ chitosan/GCE, hence a synergy between platinum and graphene functionalized with hydroxyl and epoxy is hypothesized. Chitosan also has the fundamental role of preventing the GO restacking.

The combination of $\mathrm{Pt}$ nanoparticles and graphene oxide was studied also by Shi et al. [47]. They reported a new graphene oxide $(\mathrm{GrOx}) / \mathrm{Pt}$-black nanocomposite for biosensing enhancement.

In their study they opted for the use of graphene oxide over reduced graphene, in order to avoid the anti-restacking polymers, which may reduce the active biosensing area. Graphene oxide is deposited onto a Pt/black electrode, followed by GOD immobilization.

No structural characterization of the graphene oxide is reported, but only the SEM images of the electrode which showed that the carbon-based material acted as nanoscale support for the electrodeposition of Pt-black as Pt-black grew along graphene oxide. The effective surface area of the GrOx/Pt-black microelectrode is significantly higher than for a Pt-black microelctrode with an increase in electron transfer. The new microelectrode was tested for glucose detection with excellent results in terms of sensitivity which resulted to be very high $\left(744 \mu \mathrm{A} \mathrm{mM}^{-1} \mathrm{~cm}^{-2}\right)$, while the detection limit was quite low, $1 \mu \mathrm{M}$, the linear response range between $1 \mu \mathrm{M}$ and $2 \mathrm{mM}$ and the response time $4 \mathrm{~s}$. The biosensor showed also a good stability showing a decrease of sensitivity of only $9 \%$ over 7 days storage in air at a temperature of $-20^{\circ} \mathrm{C}$.

The electrocatalytic activity defined in terms of sensitivity to $\mathrm{H}_{2} \mathrm{O}_{2}$ is 12 times better for the graphene oxide modified Pt-black electrodes compared to the unmodified ones.

Jang et al. [48] employed a $\mathrm{TiO}_{2}$-graphene composite to develop a glucose biosensor. The $\mathrm{TiO}_{2}$-graphene composite was synthesized from a colloidal mixture of $\mathrm{TiO}_{2}$ nanoparticles and GO nanosheets by an aerosol assisted self-assembly, in different $\mathrm{GO} / \mathrm{TiO}_{2}$ weight ratios. The process is carried out at a temperature of $800^{\circ} \mathrm{C}$, where thermal reduction of the GO occurs. The composite material is analyzed by SEM, XRD and XPS and shows that $\mathrm{TiO}_{2}$ is encapsulated in GR. The presence of residual oxygen from GO cannot be deduced from the XPS, due to the simultaneous presence of oxygen from $\mathrm{TiO}_{2}$.

The new $\mathrm{TiO}_{2}$-graphene composite showed better catalytic performance for glucose than a pure graphene or $\mathrm{TiO}_{2}$ biosensor. In particular, the electrocatalytic activity is better for lower $\mathrm{GR} / \mathrm{TiO}_{2}$ ratio composites, i.e. the composite covered with less GR has best performances than thick layers of crumpled GR which can obstruct the electron transfer between redox enzyme and the surface of the electrode.

The amperometric response of the glucose biosensor was linear against the concentration of glucose ranging from 0 to $8 \mathrm{mM}$ and the sensitivity of the biosensor was found to be $6.2 \mu \mathrm{Acm}^{2} \mathrm{mM}^{-1}$. These excellent results can be explained by the synergistic effect of using $\mathrm{TiO}_{2}$ nanoparticles with graphene as electrode materials due to the combination of the unique properties of both graphene and $\mathrm{TiO}_{2}$.

Very recently cobalt oxide nanoparticles $\left(\mathrm{Co}_{3} \mathrm{O}_{4}\right.$-NPs $)$ and graphene composite have been used by Karuppiah et al. [58] to modify a glassy carbon electrode for the fabrication of a novel enzymatic glucose biosensor. The graphene $/ \mathrm{Co}_{3} \mathrm{O}_{4}$ composite was prepared by hydrothermal method and characterized by SEM and XRD. The immobilized GOD showed a fast electron transfer which must be attributed to the great biocompatibility of $\mathrm{Co}_{3} \mathrm{O}_{4}$-NPs and the high conductivity of graphene itself. The realized 
glucose biosensor showed a large linear range from $0.5 \mathrm{mM}$ to $16.5 \mathrm{mM}$ with a detection limit of $0.05 \mathrm{mM}$ and a sensitivity of $13.52 \mu \mathrm{AmM} \mathrm{mm}^{-1} \mathrm{~cm}^{-2}$.

Luo et al. [60] realized a new glucose biosensor by modifying a glassy carbon electrode with a reduced graphene oxide/PAMAM/silver nanoparticles nanocomposite. It was synthesized by self-assembly of carboxyl-terminated PAMAM dendrimer (PAMAM-G3.5) on graphene oxide as growing template, and in situ reduction of both $\mathrm{AgNO}_{3}$ and $\mathrm{GO}$ under microwave irradiation. The resultant solution was filtered and the solid on the microporous membrane was redispersed in water and dropped on the surface of a GC electrode and left to dry in air. The new nanocomposite exhibited excellent "DET" properties for GOD with a rate constant of $8.59 \mathrm{~s}^{-1}$ and the analytical performances of the glucose biosensor resulted to be quite good including high sensitivity $\left(75.72 \mu \mathrm{A} \mathrm{mM}^{-1} \mathrm{~cm}^{-2}\right)$, low detection limit $(4.5 \mu \mathrm{M})$ and a good linear range from $0.032 \mathrm{mM}$ to $1.89 \mathrm{mM}$. Interferences like ascorbic acid and uric acid that usually coexist with glucose in blood samples were quite negligible to this biosensor due to the low potential applied $(-0.25 \mathrm{~V}$ vs. $\mathrm{Ag} / \mathrm{AgCl})$.

\subsection{Chemical Doping}

Chemical doping with foreign atoms is an effective method to modify the properties of graphene. Wang et al. [49] described a facile strategy to prepare N-doped graphene by using a nitrogen plasma treatment on a reduced graphene oxide substrate, dispersed in chitosan. The aim is at changing the graphene Fermi level and opening the band gap, with a consequent variation of the electrochemical activity. The quality of the graphene sheet is controlled by TEM and the doping by XPS. It comes out that the plasma treatment not only introduces nitrogen in the structure, but also increases the amount of oxygen. From N1s chemical shift it can be deduced that nitrogen is introduced in three forms: pyridinic, pyrrolic and quaternary. Residual oxygen was already present in the RGO substrate as alcohol, carbonyl and carboxylic groups. Upon plasma treatment, oxygen increases by $27.5 \%$ and also the relative ratio of the three oxygen forms changes in favor of the carbonyl group. By TEM it can be assessed that the sheet structure of RGO is preserved upon treatment.

The electrocatalysis of the so-assembled N-doped graphene electrode is probed by cyclic voltammetry and the characteristics of $\mathrm{H}_{2} \mathrm{O}_{2}$ were investigated. The reduction peak was shifted $400 \mathrm{mV}$ positively with a current of $2000 \mu \mathrm{A}$. This high performance is attributed to the high density of electronic states and the efficient quantity of free electrons that facilitate the $\mathrm{H}_{2} \mathrm{O}_{2}$ reduction. According to the authors, a crucial step in the electrocatalytic reduction, breaking the $\mathrm{O}-\mathrm{O}$ bond in $\mathrm{H}_{2} \mathrm{O}_{2}$, would become easier at the surface because the $\mathrm{N}$-doped graphene induced delocalization of graphene.
However, the non-negligible presence of oxygen is not taken explicitly into account.

The so assembled N-doped graphene electrode was also modified with GOD and tested for glucose detection. It showed fast electron transfer kinetics for GOD with high sensitivity and high selectivity. The biosensor showed a linear range between 0.1 and $1.1 \mathrm{mM}$, a detection limit of $0.01 \mathrm{mM}$ in the presence of interferences and the biosensor could be reused after 3 days with only $4 \%$ signal lost.

\subsection{CVD}

CVD graphene preparation methods are preferred when the achievement of single-layered non-oxidized graphene is an issue. It does have the disadvantage that the growth substrate must be dissolved prior to graphene use, a step which may introduce several types of defects. Furthermore, stabilizing agents must be used in the transfer process to the electrode and matrices must be employed for enzyme immobilization.

Gutés et al. [50] described the use of a single layer graphene decorated with $\mathrm{Au}$ nanoparticles by a chemical vapor deposition (CVD) using the copper substrate as source of electrons, as a biosensing platform. CVD offers the advantage of producing high-quality graphene on copper with the possibility of scaling into roll-to-roll processes. This method also allows the use of the catalytic $\mathrm{Cu}$ foil as electron source for the Au nanoparticle decoration of graphene by electroless deposition. The Raman spectrum of synthesized graphene is compatible with a single sheet. The SEM of the Au-decorated is characterized by areas of different contrast, indicating the presence of golden islands. However, the lack of chemical analysis upon the synthesis process, does not allow excluding $\mathrm{Cu}$ or Fe contaminations.

The developed graphene-based platform was tested with GOD, deposited on the top of AuNPs decorated graphene using Nafion as immobilizing matrix. The resulting biosensor showed an excellent linear range $(10-366 \mu \mathrm{M})$ with a detection limit of $4 \mu \mathrm{M}$.

Thermal chemical vapor deposition under ambient pressure, on copper tapes was used by Nguyen et al. [51] to fabricate graphene sheets. The multilayered product was, then, transferred to the layer-by-layer $\mathrm{Fe}_{3} \mathrm{O}_{4} /$ polyaniline (PANI) screen printed electrode and GOD was immobilized.

The synthesized graphene was characterized by AFM and Raman and both techniques point at the achievement of a multilayer, with 15 layers on average. It can be argued whether, in such cases the definition of nanographite is more appropriate. The developed graphene/ $\mathrm{Fe}_{3} \mathrm{O}_{4} / \mathrm{PANI} / \mathrm{GOD}$ biosensor showed much improved glucose sensitive $\left(47 \mu \mathrm{AmM}^{-1} \mathrm{~cm}^{-2}\right)$ compared to a corresponding non-graphene one $\left(10 \mu \mathrm{AmM}^{-1} \mathrm{~cm}^{-2}\right)$ and a linear range between 2.9 and $23 \mathrm{mM}$. No $L O D$ is reported in this case. 
For this type of glucose biosensor, iron contamination is certainly not a problem.

\section{Graphene-Based Non-Enzymatic Glucose Sensors}

The use of enzymes in graphene-based biosensors allowed the achievement of extraordinary performances in terms of low detection limits and high accuracies. However, there are some disadvantages such as the enzyme inactivation, the complexity of immobilization and the high cost of the enzyme itself. For these reasons, non-enzymatic graphene electrodes have been developed in recent years. Here we report ten examples for glucose detection using the same subsections used for enzymatic graphene eleectrodes regarding the electrode assembling or graphene treatment.

\subsection{Composites with Metals}

A non-enzymatic glucose sensor based on a glassy carbon electrode modified with platinum nanoflowers supported on graphene oxide (PtNFs-GO) was described by $\mathrm{Wu}$ et al. [52]. GO was prepared by the usual Hummers method followed by exfoliation. The homogeneous GO suspension and $\mathrm{K}_{2} \mathrm{PtCl}_{4}$ were mixed and the solvent ethanol acted as reductant. The dispersion of Pt on graphene sheets is very good, as shown by the TEM images. No assessment can be made on the efficacy of the reduction on GO. The PtNFs-GO was drop cast on the GC and Nafion was added to stabilize the electrode. The electrocatalytic activity of the composite is large compared to the aggregated PtNFs. This is attributed to the well distributed porous PtNFs which induces more active sites. A major role is also played by $\mathrm{GO}$, because the large presence of edge-plane like defective sites on GO could enhance the catalytic activity.

The modified electrode showed a current response towards glucose with a broad linear range from $2 \mu \mathrm{M}$ to $20.3 \mathrm{mM}$ with a detection limit of $2 \mu \mathrm{M}$ and a good stability ( $73.4 \%$ of initial response after 2 weeks of storage).

Lu et al. [53] prepared a non-enzymatic glucose sensor based on a palladium nanoparticles(PdNPs)-functionalized graphene-Nafion electrode. They prepare RGO by a variant of the Hummers method, followed by reduction with hydrazine. TE micrography and infrared spectra indicate that exfoliation and the reduction process were rather effective. Nafion is immobilized on RGO, probably as stabilizing agent. Nafion-graphene is assembled onto a glassy carbon electrode to adsorb $\mathrm{Pd}^{2+}$ Successively, also $\mathrm{Pd}^{2+}$ was reduced to hydrazine hydrate to form PdNPs in situ. Electrochemical Impedance Spectroscopy measurements show that Nafion on GC is an obstacle in the electron transfer at the interface. Impedance decreases in the graphene-nafion GC assemble and decreases further when the PdNPs are added.

The elecrocatalytic activity of the assembled sensor is evaluated by comparing the electrochemical performances in absence and in presence of glucose. A remarkable enhancement of the anodic current is observed upon addition of glucose.

The designed sensor showed wide linear range from $10 \mu \mathrm{M}$ to $5 \mathrm{mM}$, a low detection limit of $1 \mu \mathrm{M}$, good reproducibility and long term stability with a decrease of $2 \%$ of initial current response after 35 days of storage.

$\mathrm{Li}$ et al. [54] reported an enzyme-free glucose sensor based on graphene-CuO nanocomposites, synthesized on a template by a one-step chemical synthesis approach.

The synthesis of graphene oxide is the typical one from Hummers. Then, upon mixing a DMF/GO suspension with $\mathrm{Cu}\left(\mathrm{O}_{2} \mathrm{C}-\mathrm{CH}_{3}\right)_{2}$, sonication and autoclave treatment at $140^{\circ} \mathrm{C}$ for $8 \mathrm{~h}$, a nanocomposite is obtained, indicated as $\mathrm{CuO}$ /graphene. TEM, XRD and Raman characterizations of the nanocomposite show that it is a bilayer, with well dispersed $\mathrm{CuO}$ nanoparticles. However, it cannot be established whether has been thermally reduced. Modified electrodes are fabricated by suspending the $\mathrm{CuO} /$ Graphene in Nafion and drop casting the suspension on GC. EIS measurements were made on the bare electrode and on the electrodes modified with the nanocomposite/ Nafion or with $\mathrm{CuO} / \mathrm{Nafion}$. They indicate a block of the electron transfer of probe molecules at the electrode surface in the latter case. The impedance of the electrode modified with the nanocomposite is much lower, indicating that graphene facilitates the electron transfer at the electrode surface and that $\mathrm{CuO}$ nanograins are uniform and well dispersed on the graphene surface.

The electrocatalytic activity towards the oxidation of glucose was exhibited both by the $\mathrm{CuO} / \mathrm{Nafion} / \mathrm{GC}$ and, to a larger extent, by $\mathrm{CuO} / \mathrm{Graphene} / \mathrm{Nafion} / \mathrm{GC}$ electrodes. This suggests that glucose oxidation occurs at the $\mathrm{CuO}$ surface and that facilitates the catalytic process further. The enhancement of the performance may be related to the large specific surface area and efficient transport properties of graphene in the nanocomposite.

The glucose sensor showed a linear dependence from $2 \mu \mathrm{M}$ to $0.06 \mathrm{mM}$ with the excellent sensitivity of $1480 \mu \mathrm{AmM}^{-1} \mathrm{~cm}^{-2}$, very low detection limit of $0.29 \mu \mathrm{M}$, long-term stability and no significant interferences. The excellent performance can be ascribed to the uniform quantum size and good crystallinity of $\mathrm{CuO}$ nanograins, as well as the graphene acting as the synthetic template to highly disperse $\mathrm{CuO}$ nanograins on it and as the excellent electronic substrate to efficiently transport electrons.

Good results have been obtained also with another metal composite non-enzymatic glucose sensor based on a $\mathrm{Cu}$ coralloid granule/PANI/reduced GO modified GCE [55]. The nanocomposite was synthesized by using an in situ chemical oxidative polymerization method and then was cast onto the electrode surface. The amperometric response of $\mathrm{Cu} / \mathrm{PANI} / \mathrm{RGO} / \mathrm{GCE}$ showed high catalytic activity towards the oxidation of glucose with a wide linear range of $0.01-9.66 \mathrm{mM}$, a very high sensitivity of $603.59 \mu \mathrm{A} \mathrm{cm}^{-2} \mathrm{mM}^{-1}$ and low detection limit of $1.34 \mu \mathrm{M}$.

Wang et al. [61] proposed for the first time nickelcobalt nanostructures (Ni-Co NSs) based sensor constructed on a RGO nanosheets modified GC electrode as 
a nonenzymatic glucose sensor. RGO nanosheets were assembled onto the GC electrode surface through $\pi-\pi$ electronic interactions and successively flower-like Ni-Co NSs were constructed onto the $\mathrm{RGO} / \mathrm{GC}$ electrode by dynamic potential scan. The so modified electrode showed the best catalytic activity toward oxidation of glucose at the potential scan number of 20 and a $\mathrm{Ni}^{2+} / \mathrm{Co}^{2+}$ molar ration of $1: 1$. The sensor showed a very high sensitivity of $1773.61 \mu \mathrm{A} \mathrm{cm} \mathrm{cm}^{-1}$, a wide linear range between $10 \mu \mathrm{M}$ to $2.65 \mathrm{mM}$ with a detection limit of $3.79 \mu \mathrm{M}$. Furthermore, the proposed sensor showed also high selectivity and very good stability as it showed a current decrease of $3.8 \%$ after 45 days if stored at room temperature.

Very recently Wang et al. [62] described a highly sensitive glucose sensor based on 3D dendritic copper-cobalt nanocomposites ( $\mathrm{Cu}-\mathrm{Co} \mathrm{NSs}$ ) electrodeposited on the RGO-chitosan/GC electrode by a potentiostatic deposition method. The RGO-chitosan improved the conductivity of 3D dendritic $\mathrm{Cu}-\mathrm{Co} \mathrm{NSs}$ and the doping of Co resulted in $3 \mathrm{D}$ dendritic porous $\mathrm{Cu}-\mathrm{Co} \mathrm{NSs}$ with a large specific surface area which enhanced the electron and mass transfer. The synergistic effect between $\mathrm{Cu}$ and $\mathrm{Co}$ resulted in a good catalytic activity and a low electrocatalytric oxidation potential for glucose. Therefore, the resulting nonenzymatic glucose sensor showed an excellent sensitivity of $1921 \mu \mathrm{A} \mathrm{cm}^{-2} \mathrm{mM}^{-1}$, a linear range between 0.015 and $6.95 \mathrm{mM}$ and a low detection limit of $10 \mu \mathrm{M}$.

A new glucose sensor has been fabricated by Sun et al. [63] based on a composite film prepared from Nickel(II) ion, quercitin and graphene. Results demonstrated that the sensor has a good ability toward the catalytic oxidation of glucose, which showed fast electron transfer kinetics (rate constant $=5.4 \mathrm{~s}^{-1}$ ) and excellent electrocatalytic activity for glucose $\left(k_{\text {cat }}=2.93 \times 10^{3} \mathrm{M}^{-1} \mathrm{~s}^{-1}\right)$. The electrochemical response was linear over the wide glucose concentration range of $3 \mu \mathrm{M}$ to $900 \mu \mathrm{M}$. The sensor showed a detection limit of $0.5 \mu \mathrm{M}$ and a sensitivity of $2671.43 \mu \mathrm{A} \mathrm{mM}^{-1} \mathrm{~cm}^{-2}$.

\subsection{Chemical Doping}

Kong et al. [56] reported an example of chemical doping but for a non-enzymatic glucose sensor. Reduced GO has been first assembled with Co nanosheets and then the prepared $\mathrm{Co} / \mathrm{RGO}$ was doped with nitrogen by a hightemperature nitridation technique, instead of using the plasma treatment as for the enzymatic glucose biosensor previously described [49]. The analytical performances of the related glucose sensor were very good with a detection limit of $6.93 \mu \mathrm{M}$, an excellent sensitivity of $1.17 \mathrm{~mA} \mathrm{mM}^{-1} \mathrm{~cm}^{-2}$, a linear range between 0.01 and $4.75 \mathrm{mM}$ and a response time of $5 \mathrm{~s}$. These good performances can be explained by considering the strong synergistic effect between $\mathrm{Co} / \mathrm{RGO}$ and $\mathrm{N}$-doped RGO.

\subsection{CVD}

Dong et al. [57] reported the synthesis of a 3D graphene foam grown by CVD for the construction of a new enzymeless glucose sensor based on a $3 \mathrm{D}$ graphene $/ \mathrm{Co}_{3} \mathrm{O}_{4}$ nanowire composite. The graphene foam serves as a $3 \mathrm{D}$ support to anchor $\mathrm{Co}_{3} \mathrm{O}_{4}$ which is able to catalyze glucose oxidation. The synergistic cooperation between graphene and the metal oxide is responsible for the excellent electrochemical performances shown by this sensor, which can detect glucose with a ultrahigh sensitivity of $3.39 \mathrm{~mA}$ $\mathrm{mM}^{-1} \mathrm{~cm}^{-2}$ and a remarkable lower detection limit of $0.025 \mu \mathrm{M}$. The performances showed by graphene $/ \mathrm{Co}_{3} \mathrm{O}_{4}$ composite based sensor were the best among all those obtained either with enzymatic or non-enzymatic biosensors scanned in this review for glucose detection.

\subsection{Graphene Structure/Sensor Performance Relationships}

In this review, we presented a small fraction of the electrochemical studies made so far, involving graphene. In order to limit the number of papers, we selected sensors only for glucose detection. Although the number of cases is apparently limited, the type of graphene, graphene production and/or electrode assembly with graphene is, on the other side, quite large.

The reasons behind such variability are the lack of a defect-free preparation method of large quantities of graphene and the intrinsic tendency of graphene to agglomerate and restack. This obliges to find strategies of preparation, transfer and assembling of graphene electrodes that inevitably affect the working mechanism.

Defects in the graphene structure are preparation-dependent. Preparation by oxidation methods leave oxygen mostly at the edges of the graphene planes. In Scheme 1 different outcomes are presented for preparation mostly used in graphene-based electrodes. Panel (a) is a sketch of a pure defect-less graphene sheet. In panel (b) a graphene sheet with some type of dislocations is reported, where 5- and 7- membered rings can be observed. The graphene synthesis through oxidation leaves on the edges oxidation groups of different types: alcohol, epoxy, diols, aldehydes, ketones and carboxylic groups, which may all be present to a different extent depending on the preparation procedure as sketched in panel (c). Preparation by nitrogen-plasma doping yields pyrrolic, pyrrolidic as well as quaternary nitrogen atoms in the graphene structure (panel d), but care must be taken in this case, because upon plasma treatment also the amount of oxidation species increases. The fundamental reason for employing graphene and/or graphene derivatives in assembling electrodes is related to the high conductivity as well as high surface area. These are really crucial points in the choice of the type of graphene to use. The in plane-conductivity of $\mathrm{GO}$ is lower than for pure graphene. However, compared to RGO, GO has a large surface area. Furthermore, GO may easier immobilize enzymes through amidic bonds. 
a)

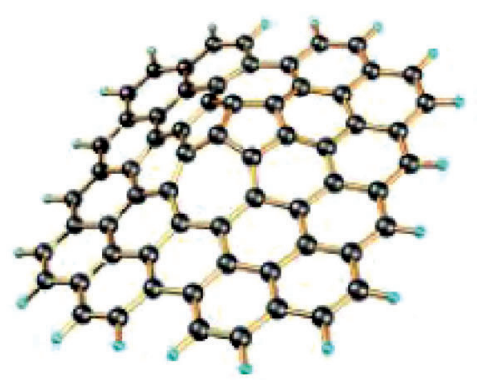

c)

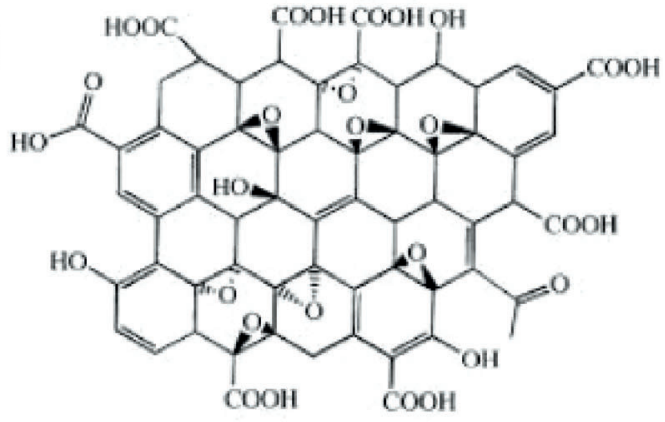

e)

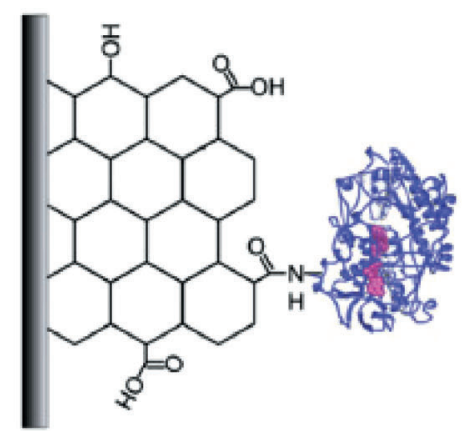

g)

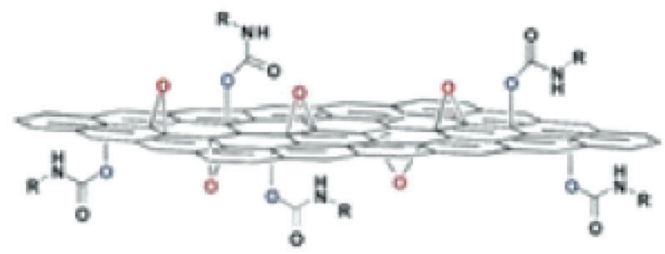

b)

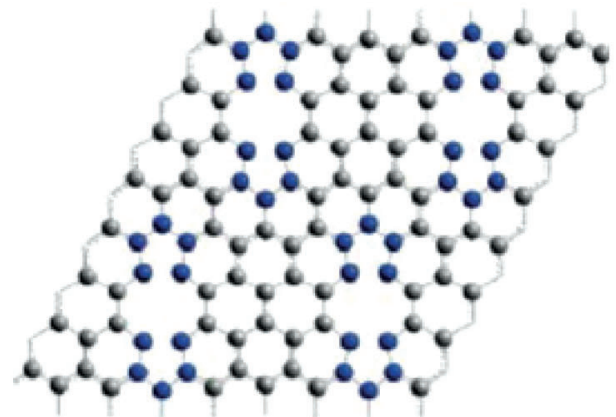

d)

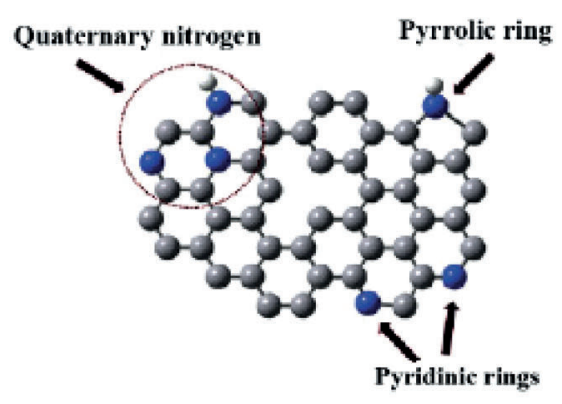

f)

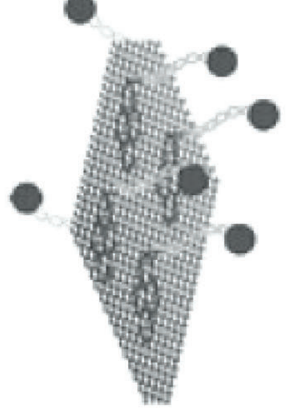

h)

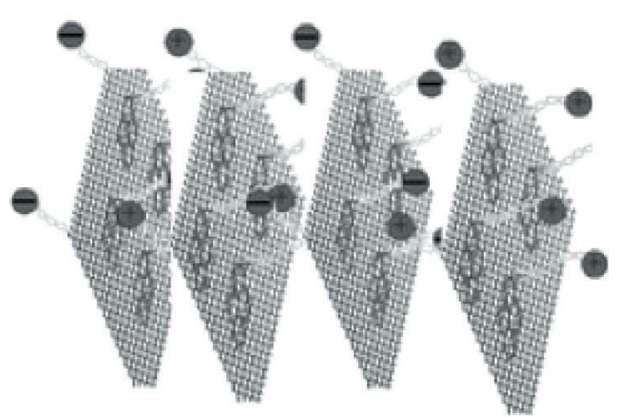

Scheme 1. Schematic representation of (a) defectless graphene; (b) graphene with 5-8-5 defect structure; (c) graphene oxide; (d) Ndoped graphene with quaternary nitrogen, pyrrolic and pyridinic rings; (e) graphene oxide-glucose oxidase amidic bonds; (f) graphene oxide polymer $\pi-\pi$ stacking type interactions; (g) graphene oxide polymer bonds by direct conjugation through oxygen atoms; (h) alternately charged layer-by-layer 3D graphene structure.

At this point, it seems appropriate to make a clarification. All articles cited in this review and reported in Tables 1 and 2 describe the construction of glucose sen- sors based on "graphene". It is always either (not always clearly specified and called with the generic term "graphene") or RGO. It is possible to make an initial consid- 
eration: in the case of enzymatic biosensors it can be seen that the best results in terms of electrochemical performances such as $L O D$ and sensitivity of the biosensor are obtained using GO. Clearly, the possibility of GO to tightly bind the enzymes through the formation of amidic bonds with the oxidation groups plays a crucial role (Scheme 1, panel e). Instead, in the case of non-enzymatic sensors good results were obtained both with GO and RGO $[53,55,56]$. These results could be ascribed to the fact that RGO is more similar to pristine graphene than GO and therefore should show, in principle, better conductive properties compared to $\mathrm{GO}$, altough the reduction of GO to RGO has often resulted in relatively poor yields in terms of surface area and electronic conductibility. For these reasons, in the case of non-enzymatic sensors, when there is not the crucial point of the enzyme immobilization which occurs definitely better with GO, it is not possible to know "a priori" if it is better to use GO or RGO for sensor construction because the electrochemical performances of RGO can markedly vary depending on the method of reduction employed.

Going through the papers, it was clear that RGO has variable characteristics strongly dependent on the type of preparation and may leave oxidation groups to a different extent, related to the exact experimental conditions. As mentioned above, some biosensor assembling do rely on the presence of residual oxidation groups on graphene for enzyme immobilization (Scheme 1 panel e). Therefore, the reduction of the GO may be considered more as a way of changing the total amount of oxidation groups at the expense of the total surface area, then a procedure for complete oxygen removal.

Another important consideration can be made. In all studies scanned for this review, the graphene based electrodes have been assembled according to five different treatments, specified in the first column of Tables 1 and 2: direct drop casting onto the electrode surface, in contact with metals to create composite materials, modified with polymers, chemical doping or CVD also in the presence of metals and/or polymers.

The best results for the glucose (bio)sensors analyzed in this review have been obtained with metal composites for both enzymatic and non-enzymatic sensors. In particular, optimal electrocatalytic properties in terms of high sensitivity, low $L O D$ and good stability have been achieved with $\mathrm{Pt} /$ graphene/chitosan [46] and GO/Pt-black [47] nanocomposites for the enzymatic glucose biosensors and with graphene-CuO [54] and $\mathrm{Cu} / \mathrm{PANI} / \mathrm{RGO}$ [55] for the non-enzymatic ones. The excellent performances can be ascribed to the synergistic effects of the metal-graphene composite for both Pt-NPs/graphene [46] and GO/ Pt-black [47] nanocomposites. These effects might be attributed to the large surface area of graphene, the fast electron transfer activity of the metal-graphene composite which minimize mass transport limitations and the electrocatalytic synergy from platinum and graphene. As for the non-enzymatic sensors, the high conductivity and big specific area of graphene combined with the good crystal- linity of $\mathrm{CuO}$ as well as the ability of graphene itself to highly disperse $\mathrm{CuO}$ nanograins in the template for the first sensor [54] and the synergistic effects of $\mathrm{Cu}$ coralloid granules and graphene itself in the second one [55] are responsible for the excellent electrocatalysis.

The role of polymers must also be carefully evaluated. Their use as dispersing/stabilizing agents is mandatory when hydrophobic graphene is used. The interaction may be of the dipole-dipole, dipole-charge or even by $\pi-\pi$ stacking type, if the polymers have aromatic groups (Scheme 1 panel f). This inevitably hinders graphene conductivity and limits active area of the sensors. This is confirmed by the results reported in Tables 1 and 2. No excellent performances were registered when graphene is used modified with polymers with no metal added. When used with GO, polymers, similarly enzymes, may bind in a stable way by direct conjugation (Scheme 1 panel g). Here, we have again a different interaction mechanism also between dispersing agents and graphene, that depends on the type of graphene, and may have a role in the electron transfer process at the electrode. However, any significant improvement has been obtained with all polymer functionalized graphene based biosensors scanned in this review.

An indirect evaluation of the balance between improvement/hindering of using polymers is obtained in 3D graphene-structures, where a layer-by-layer structure is built, by alternating polymer-conjugated graphene layers to non-conjugated polymers of a different type (Scheme 1 panel $\mathrm{h}$ ). The performance is a function of the number of layers and gives the balance between improvement due to improved conductivity and hindrance due to the reduction of sensor active area and the traveling distance of the electron in the electron transfer process.

It is interesting to note that a marked improvement of the electrochemical performances of the sensor is observed when a metal is included in the polymer-graphene structure, as confirmed by the results obtained for example for the glucose sensors based on Pt/graphene/chitosan [46] and $\mathrm{CuO} / \mathrm{Nafion} /$ graphene [54] which showed very low $L O D$ values, $0.6 \mu \mathrm{M}$ and $0.29 \mu \mathrm{M}$, respectively. Also the glucose sensor based on $\mathrm{Cu} / \mathrm{PANI} / \mathrm{RGO}$ [55] can be distinguished from the others for the high value of sensitivity $\left(603.59 \mu \mathrm{Acm}^{-2} \mathrm{mM}^{-1}\right)$.

A completely separate situation must be stated for doped graphene, where defects are introduced on purpose to change the density of states. Among different foreign atoms, nitrogen doping plays a critical role in regulating the electronic properties of graphene. The associated problem for $\mathrm{N}$-doping is that oxygen is also introduced and the effect of the dopant and the "pollutant" cannot be disentangled. Nevertheless, the results obtained for the application of $\mathrm{N}$-doped graphene in electrochemical sensing are very encouraging. Good results have been obtained with an $\mathrm{N}$-doped graphene electrode synthesized through nitrogen plasma treatment of graphene. The Ndoped graphene showed very fast electron transfer kinetics for glucose sensing to concentrations as low as 
$0.01 \mathrm{mM}$ [49]. Even better results have been obtained with a $\mathrm{N}$-doped graphene assembled with $\mathrm{Co}$ nanosheets for glucose sensing [56]. The $\mathrm{N}$-doped graphene has been prepared in this case by high-temperature nitridation and the very good results obtained in terms of very high sensitivity $\left(1.17 \mathrm{~mA} \mathrm{~cm}^{-2} \mathrm{mM}^{-1}\right)$ are due to the synergistic effect between Co nanosheets and N-doped GO. Finally, it should be noted that the CVD is just a method of graphene preparation which should produce, in principle, relatively high quality single-layered graphene even if sometimes some defects are introduced. Therefore, the CVD produced graphene does not necessarily ensure the best electrochemical performances as demonstrated by the articles examined in this review: only if graphene is suitably functionalized with metals, regardless of the production method, it is able to enhance the electrochemical performances as clearly shown, for example, by the glucose sensor based on CVD produced graphene $/ \mathrm{Co}_{3} \mathrm{O}_{4}$ capable to detect glucose with a ultrahigh sensitivity $\left(3.39 \mathrm{~mA} \mathrm{mM}^{-1} \mathrm{~cm}^{-2}\right)$ and a very low detection limit (25 nM) [57].

\section{Graphene-Based and Graphene-Less Sensors: a Critical Comparison}

The performances of all graphene-containing electrodes, however assembled, scanned in this review, are definitely better than their corresponding graphene-less ones with graphite or other carbon materials for both enzymatic and non-enzymatic sensors. In all forms, graphene seems to improve the electrode performances.

As an example, we compare the results obtained with or without graphene for some of the sensors reported in the previous section $[46,47,54,55]$ which showed the best electrochemical performances.

In the case of the enzymatic glucose biosensor based on a Pt NPs/graphene/chitosan GC electrode [46] the magnitude of the electrochemical response has been carefully investigated and compared with that obtained with a graphene/chitosan/GCE without PtNPs and with that obtained with a bare GCE. The magnitude of the electrochemical response strongly increased in the following order: $\mathrm{GC}<$ graphene/chitosan/GC $<$ Pt/graphene/chitosan/ $\mathrm{GC}$, thus demonstrating that the hybrid nanocomposite film with both graphene and PtNPs effectively showed a marked synergistic effect on the electrocatalytic activity of $\mathrm{H}_{2} \mathrm{O}_{2}$, which is the electroactive intermediate for GOD based biosensors. It must also be noted a decrease in the overpotential of $\mathrm{H}_{2} \mathrm{O}_{2}$ when a Pt/graphene/chitosan/GCE is used. Also this effect can be ascribed to the electrocatalytic activity of both PtNPs and graphene.

Similar results have been reported by Shi et al. [47] for the graphene oxide/Pt-black based glucose sensor. Cyclic voltammograms have been recorded for unmodified and graphene oxide-modified $\mathrm{Pt}$ microelectrodes and the large difference in shape clearly demonstrated that the effective surface area of the unmodified microelectrodes was significantly increased upon graphene modification.
In particular, GO/Pt-black modified electrodes exhibited a 12-time larger effective surface area than that of Ptblack modified electrodes which resulted to be in turn $2.6 \times 10^{4}$ times higher compared to unmodified microelectrodes.

The results are similar in the case of non-enzymatic glucose sensors. In the paper reported by Li et al. [54] describing a glucose sensor based on graphene/CuO nanocomposite an accurate study has been carried out by recording cyclic voltammograms of a bare GCE, CuO/GCE and graphene/CuO/GCE. Compared with the bare GCE the graphene/CuO/GCE displayed much larger peak currents which are approximately twice than those registered with the $\mathrm{CuO} / \mathrm{GCE}$ without graphene. This enhanced performance may be due, as already reported in this review, to the large specific surface area of graphene, combined with the good crystallinity and efficient transport properties of graphene which is able to promptly and swiftly transport electrons from $\mathrm{CuO}$ nanograins on itself.

Also in the case of the non-enzymatic glucose sensor based on $\mathrm{Cu} / \mathrm{PANI} / \mathrm{RGO}$ nanocomposite [55] the electrochemical behavior of a bare GCE, Cu/PANI/RGO/GCE, $\mathrm{Cu} / \mathrm{RGO} / \mathrm{GCE}, \mathrm{Cu} / \mathrm{PANI} / \mathrm{GCE}$ and $\mathrm{Cu} / \mathrm{GCE}$ have been accurately compared. The electroactive surface area has been carefully calculated in each case and resulted to be $0.056 \mathrm{~cm}^{2}, 0.066 \mathrm{~cm}^{2}, 0.051 \mathrm{~cm}^{2}, 0.041 \mathrm{~cm}^{2}$ and $0.026 \mathrm{~cm}^{2}$, respectively. Once again, it can be noted that the $\mathrm{Cu}$ / PANI/RGO/GCE showed the largest surface area among all the studied materials, which resulted to be about 2.5 times higher than that of the $\mathrm{Cu} / \mathrm{GCE}$. The reason was that $\mathrm{RGO} / \mathrm{PANI}$ provided a large surface area to form $\mathrm{Cu}$ coralloid granules, that in turn led to more active sites which could enhance the electrocatalytic performance of $\mathrm{Cu} / \mathrm{PANI} / \mathrm{RGO} / \mathrm{GCE}$ toward glucose oxidation.

A quantitative assessment of the graphene effect in modified electrodes can be attempted through the evaluation and comparison of the rate constants, for those papers where they are reported. In the case of enzymatic sensors, it has been established that "DET" reaction of GOD is a two electron coupled with two-proton reaction. In some cases the apparent "DET" transfer rate constant, i.e. the transfer between the bound FAD and the electrode, is estimated according to the Laviron's equation [35] if the difference between anodic and cathodic peaks is lower than $200 \mathrm{mV}$. The values reported in the papers we have examined in the previous sections range between $2.68 \mathrm{~s}^{-1}$ for GC electrodes modified with RGO, dispersed in water and, then, deposited on the bare electrode [59] and $8.59 \mathrm{~s}^{-1}[60]$ for GC electrodes modified with RGO, and silver nanoparticles in PAMAM polymer. Other systems, are characterized by an apparent constant of $2.83 \mathrm{~s}^{-1}$ [34], where the dispersion of graphene is achieved by chitosan, $3.52 \mathrm{~s}^{-1}$ where $\mathrm{Co}_{3} \mathrm{O}_{4}$ nanoparticles are employed [58] and $5.9 \mathrm{~s}^{-1}$ where CdS nanoparticles are used [45]. Though care must be taken in comparing these values, since the sensors are assembled in different conditions, considerations can be made on the positive, synergistic effects of the metal, metal oxide or metal sulfide 
Table 3. Comparison of apparent rate constants of various enzymatic biosensors for glucose detection, based on graphene or on other carbon nanostructured materials. DHDP: dihexadecylphosphate; CoTTP: coporphyrins. Where published, the errors on the rate constants are reported.

\begin{tabular}{|c|c|c|c|c|}
\hline Carbon nanostructured material & Apparent rate constant $\left(\mathrm{s}^{-1}\right)$ & Type of electrode & Polymer & Reference \\
\hline$\overline{\mathrm{Gr}}$ & 2.68 & GC & & [59] \\
\hline $\mathrm{Gr}$ & $2.83 \pm 0.18$ & $\mathrm{GC}$ & Chitosan & {$[34]$} \\
\hline $\mathrm{Gr} / \mathrm{Co}_{3} \mathrm{O}_{4}$ & 3.52 & GC & & {$[58]$} \\
\hline $\mathrm{Gr} / \mathrm{CdS}$ & 5.9 & $\mathrm{GC}$ & & [45] \\
\hline $\mathrm{RGO} / \mathrm{Ag}$ & 8.59 & $\mathrm{GC}$ & PAMAM & [60] \\
\hline SWCNTs & 3.0 & GC & Chitosan & [64] \\
\hline SWCNTs/CoTTP & 1.01 & GC & Nafion & {$[65]$} \\
\hline MWCNTs & 1.08 & GC & Chitosan & {$[36]$} \\
\hline MWCNTs & 1.16 & GC & & {$[66]$} \\
\hline Boron/MWCNTs & 1.56 & GC & & {$[66]$} \\
\hline MWCNTs & $1.69 \pm 0.05$ & GC & DHDP & [67] \\
\hline MWCNTs $/ \mathrm{SnS}_{2}$ & 3.96 & GC & Nafion & [68] \\
\hline MWCNTs & 11.03 & $\mathrm{Au}$ & Chitosan & [69] \\
\hline SWCNHs & 3.0 & GC & Nafion & [70] \\
\hline
\end{tabular}

Table 4. Comparison of apparent rate constants and kinetic constants of some non-enzymatic biosensors for glucose detection, based on graphene or on other carbon nanostructured materials.

\begin{tabular}{|c|c|c|c|c|c|}
\hline $\begin{array}{l}\text { Carbon nanostructured mate- } \\
\text { rial }\end{array}$ & $\begin{array}{l}\text { Kinetic rate constant } \\
\left(\mathrm{L} \mathrm{mol}^{-1} \mathrm{~s}^{-1}\right)\end{array}$ & $\begin{array}{l}\text { Apparent rate constant } \\
\left(\mathrm{s}^{-1}\right)\end{array}$ & $\begin{array}{l}\text { Type of elec- } \\
\text { trode }\end{array}$ & Polymer & Reference \\
\hline Graphene/Ni-Co & $1.79 \times 10^{4}$ & - & $\mathrm{GC}$ & - & [61] \\
\hline $\mathrm{GO} / \mathrm{Cu}-\mathrm{Co}$ & $4.98 \times 10^{1}$ & - & $\mathrm{GC}$ & Chitosan & [62] \\
\hline Graphene /Ni & $2.93 \times 10^{3}$ & 5.4 & GC & Quercetin & [63] \\
\hline MWCNTs/CuO & $8.2 \times 10^{3}$ & - & Carbon Ceramic & Polypyrrole & [72] \\
\hline MWCNTs/Cu & - & $0.27-0.32$ & GC & Nafion & [73] \\
\hline
\end{tabular}

nanoparticles. A tentative comparison a kinetic performances can also be made with sensors assembled with other nanostructures materials, though, under the same premises.

An overview is presented in Table 3, where the apparent rate constant for glucose oxidation is reported together with the material used for modifying the electrode, the type of electrode, and, where applicable, the composite material and the dispersing polymer. In general, the rate constants obtained by using single walled carbon nanotubes (SWCNTs), some of the multi walled carbon nanotubes (MWCNTs) and the nanohorns (SWCNHs), are lower or equal, within the experimental error, than those obtained with graphene. In particular, an error up to two orders in magnitude in the rate constant, as for the graphene/chitosan case [34] brings the sensors based on graphene of references [59] and [34], as well as the ones based on SWCNTs [60] and on SWCNHs [70] to comparable kinetic performances (nearly $3.0 \mathrm{~s}^{-1}$ ). Applying a similar criterion, SWCNTs/porphyrins [65], MWCNTs [66] and MWCNTs with chitosan [66] sensors show similar kinetic performances and lower than any graphene based sensor (1.0 to $1.56 \mathrm{~s}^{-1}$ ). MWCNTs/dihexadecylphosphate, with a rate constant of $1.69 \mathrm{~s}^{-1}$ also belongs to this group, but the error in this case is reported and it is equal to $\pm 0.05 \mathrm{~s}^{-1}$. The other graphene-based sensors all have higher constants, an exception being some of the sensors prepared with MWCNTs. The preparation with $\mathrm{SnS}_{2}$ nanoflakes and Nafion [68] displays a rate constant of $3.96 \mathrm{~s}^{-1}$, slightly higher than most of the graphene sensor. The assembling with MWCNTs chitosan has the highest rate constant all the examples shown in the dihexadecylphosphate Table. In this sensor a gold electrode is used and compared with all the other sensors, where a GC electrode is employed and this may play a crucial role in the kinetics of the electron transfer process.

Quantitative catalytic data on non-enzymatic sensors are more scarce and less homogenous. In some of the papers an evaluation of the electrocatalytic performances are made through chronoamperometry, which gives a catalytic constant, $K_{\text {cat }}$, according to the equation proposed by Bard and Faulkner [71] in diffusion control processes. In one of the papers also the apparent kinetic constant calculated by the Laviron equation is included. Comparative data are also too few for any significant consideration. An overview of the available data is given in Table 4.

\section{Conclusions}

Graphene very often plays a positive role in the performances of graphene-based electrodes. The materials actually employed in the electrode assembly may have defects of different types and require dispersing, stabilizing agents. In all cases the performances improve with respect to the non-graphene based corresponding electrodes. The positive correlation hints at the co-existence 
of different electron-transfer mechanisms at the electrode, which balance the effects related to the properties of each material, such as the reduction of conductivity in oxygenated species and the lack of anchoring points in the "perfect" surface. The disentangling of the different mechanisms may be achieved only with a systematic study, where the same preparation of graphene is subject of subsequent treatments and at each step the same electrode assembling is performed and tested for electrochemical performances.

However, although in this review different types of graphene have been compared, it is possible to conclude that graphene-based sensors for glucose detection actually show better performances than their corresponding graphene-less ones and that surely the best results in terms of sensor sensitivity and detection limit are obtained when metal nanoparticles are co-immobilized with graphene, sometimes in presence of a proper conductive polymer. This trend is also exhibited in the apparent rate constant of the glucose oxidation process. In comparison with other nanostructured materials, graphene-based glucose (bio)sensors often provide the best performances, the only exception being the MWCNTs in specific assembles.

\section{Acknowledgements}

This authors thank The Swedish Research Council for financial support.

\section{References}

[1] E. Fitzer, K-H. Kochling, H. P. Boehm, H. Marsh, Pure Appl. Chem. 1995, 67, 491.

[2] A. K. Geim, K. S. Novoselov, Nat. Mater. 2007, 6,183.

[3] D. Li, M. B. Muller, S. Gilje, R. B. Kaner, G. G. Wallace, Nat. Nanotech. 2008, 3, 101.

[4] W. S. Hummers, R. E. Offeman, J. Am. Chem. Soc. 1958, 80, 1339.

[5] M. J. McAllister, J-L. Li, D. H. Adamson, H. C. Schniepp, A. A. Abdala, J. Liu, M. Herrera-Alonso, D. L. Milius, R. Car, R. K. Prud'homme, I. A. Aksay, Chem. Mater. 2007, 18, 4396.

[6] H. C. Schniepp, J-L. Li, M. J. McAllister, H. Sai, M. Herrera-Alonso, D. H. Adamson, D. L. Milius, R. K. Prud'homme, R. Car, D. A. Saville, I. A. Aksay, J. Chem. Phys. 2006, 110,8535 .

[7] M. Cai, D. Thorpe, D. H. Adamson, H. S. Schniepp, J. Mater. Chem. 2012, 22, 24992.

[8] V. Loryuenyong, K. Totepvimarn, P. Eimburanapravat, W. Boonchompoo, A. Buasri, Adv. Mater. Sci. Eng., 2013, ID 923403.

[9] J. C. Meyer, A. K. Geim, M. I. Katsnelson, K. S. Novoselov, T. J. Booth, S. Roth, Nature 2007, 446, 60.

[10] A. C. Ferrari, J. C. Meyer, V. Scardaci, C. Casiraghi, M. Lazzeri, F. Mauri, S. Piscanec, D. Jiang, K. S. Novoselov, S. Roth, A. K. Geim, Phys. Rev. Lett. 2006, 97, 187401.

[11] K. N. Kudin, B. Ozbas, H. C. Schniepp, R. K. Prud'homme, I. A. Aksay, R. Car, Nano Lett. 2008, 8, 36.
[12] D. Yang, A. Velamakanni, G. Bozoklu, S. Park, M. Stoller, R. D. Piner, S. Stankovich, I. Jung, D. A. Field, C. A. jr Ventrice, R. S. Ruoff, Carbon 2009, 47, 145.

[13] S. Kaciulis, A. Mezzi, P. Calvani, D. M. Trucchi, Surf. Interf. Anal. 2014, 46, 966-969.

[14] U. Wollenberger, in Comprehensive Analytical Chemistry (Ed: D. Barcelo), Vol. 44, Biosensors and Modern Biospecific Analytical Techniques (Ed: L. Gorton), Elsevier, Amsterdam, 2005, pp. 65-130.

[15] E. F. Ferapontova, S. Shleev, T. Ruzgas, L. Stoica, A. Christenson, J. Tkac, A. I. Yaropolov, L. Gorton, Perspect. Bioanal. 2005, 1, 517.

[16] Y. Liu, Y. Du, C. M. Li, Electroanalysis 2013, 25, 815.

[17] M. Falk, Z. Blum, S. Shleev, Electrochim. Acta 2012, 82, 191.

[18] M. Pumera, Chem. Rec. 2009, 9, 211.

[19] A. Ambrosi, M. Pumera, Nanoscale 2014, 6, 472.

[20] X. Yang, J. Zhu, L. Qiu, D. Li, Adv. Mater. 2011, 23, 2833.

[21] R. L. McCreery, Chem. Rev. 2008, 108, 2646.

[22] J. Shi, T. Cha, J. Clausen, A. Diggs , J. H. Choi, D. M. Portefield, Analyst 2011, 136, 4916.

[23] R. Antiochia, L. Gorton, Sens. Actuators B 2014, 195, 287.

[24] X. Zhao, Y. Du, W. Ye, D. Lu, X. Xia, C. Wang, New. J. Chem. 2013, 37, 4045.

[25] T. M. B. F. Oliveira, M. F. Barroso, S. Morais, M. Araújo, C. Freire, P. Lima-Neto, A. N. Correia, M. B. P. P. Oliveira, C. Delerue-Matos, Biosens. Bioelectron. 2013, 47, 292.

[26] F. Valentini, D. Romanazzo, M. Carbone, G. Palleschi, Electroanalysis 2012, 24, 872.

[27] F. Valentini, D. Roscioli, M. Carbone, V. Conte, B. Floris, G. Palleschi, R. Flammini, E. M. Bauer, G. Nasillo, E. Caponetti, Anal. Chem. 2012, 84, 5823.

[28] R. Ludwig, W. Harreither, F. Tasca, L. Gorton, ChemPhysChem 2010, 11, 2674.

[29] R. Ludwig, R. Ortiz, C. Schulz, W. Harreither, C. Sygmund, L. Gorton, Anal. Bioanal. Chem. 2013, 405, 3637.

[30] C. Shan, H. Yang, J. Song, D. Han, A. Ivaska, L. Niu, Anal. Chem. 2009, 81, 2378.

[31] N. Kotyukhova, P. J. Ollivier, B. J. Martin, T. E. Mallouk, S. A. Chizhik, E. V. Buzaneva, A. D. Gorchinskiy, Chem. Mater. 1999, 11, 771.

[32] K. Hasan, M. H. Asif, O. Nur, M. Willander, J. Biosens. Bioelectron. 2012, 3, 114.

[33] G. Zeng, Y. Xing, J. Gao, Z. Wang, X. Zhang, Langmuir 2010, 26, 15022.

[34] X. Kang, J. Wang, H. Wu, I. A. Akasay, J. Liu, Y. Lin Y, Biosens. Bioelectron. 2009, 25, 901.

[35] E. Laviron, J. Electroanal. Chem. 1979, 101, 19.

[36] X. Luo, A. J. Killiard, M. R. Smyth, Electroanalysis 2006, $18,1131$.

[37] B. Unnikrishnan, S. Palanisamy, S-M. Chen, Biosens. Bioelectron. 2013, 39, 70 .

[38] M. Zhou, Y. Zhai, S. Dong, Anal. Chem. 2009, 81, 5603.

[39] S. Alwarappan, C. Liu, A. Kumar, C-Z. Li, J. Phys. Chem. C 2010, 114, 12920.

[40] B. Liang, L. Fang, G. Yang, Y. Hu, X. Guo, X. Ye, Biosens. Bioelectron. 2013, 4, 131.

[41] C. Shan, H. Yang, D. Han, Q. Zhang, A. Ivaska, L. Niu, Biosens. Bioelectron. 2010, 25, 1070.

[42] K. Zhou, Y. Zhu, X. Yang, C. Li, Electroanalysis 2010, 22, 259.

[43] Y. C. Si, E. T. Samulski, NanoLett. 2008, 8, 1679.

[44] Y. L. Yao, K. K. Shiu, Electroanalysis 2008, 20, 1542.

[45] K. Wang, Q. Liu, Q-M. Guan, J. Wu, H-N. Li, J-J. Yan, Biosens. Bioelectron. 2011, 26, 2252.

[46] H. Wu, J. Wang, X. Kang, C. Wang, D. Wang, J. Liu, I. Aksay, Y. Lin, Talanta 2009, 80, 403. 
[47] J. Shi, H. Zhang, A. Snyder, M-X. Wang, J. Xie, D. M. Porterfield, L. A. Stanciu, Biosens. Bioelectron. 2012, 38, 314.

[48] H. D. Jang, S. K. Kim, H. Chang, K-M. Roh, J-W. Choi, J. Huang, Biosens. Bioelectron. 2012, 38, 184.

[49] Y. Wang, Y. Shao, D. W. Matson, J. Li, Y. Lin, ACS Nano, 2010, 4, 1790.

[50] A. Gutés, C. Carraro, R. Maboudian, Biosens. Bioelectron. 2012, 33, 56.

[51] H. B. Nguyen, V. C. Nguyen, V. T. Nguyen, T. T. T. Ngo, N. T. Nguyen, T. T. H. Dang, D. L. Tran, P. Q. Do, X. N. Nguyen, X. P. Nguyen, H. K. Phan, N. M. Phan, Nanosci. Nanotechnol. 2012, 3, 025011.

[52] G-H. Wu, X-H. Song, Y-F. Wu, X-M. Chen, F. Luo, X. Chen, Talanta 2013, 105, 379.

[53] L-M. Lu, H-B. Li, F. Qu, X-B. Zhang, G-L. Shen, R-Q. Yu, Biosens. Bioelectron. 2011, 26, 3500.

[54] Y. Li, F. Huang, J. Chen, T. Mo, S. Li, F. Wang, S. Feng, Y. $\mathrm{Li}$, Int. J. Electrochem. Sci. 2013, 8, 6332.

[55] X. Lu, Y. Ye, Y. Song, S. Chen, P. Li, L. Chen, L. Wang, Anal. Meth. 2014, 6, 4643.

[56] L. Kong, Z. Ren, J. Wu, H. Fu, Chem Commun. 2014, 50, 4921.

[57] X-C. Dong, H. Xu, X-W. Wang, Y-X. Huang, M. B. ChanPark, H. Zhang, L-H. Wang, W. Huang, P. Chen, ACS Nano, 2012, 6, 3206.

[58] C. Karuppiah, S. Palanisamy, S-M. Chen, V. Veeramani, P. Periakaruppan, Sens. Actuators B 2014, 196, 450

[59] P. Wu, Q. Shao, Y. Hu, J. Jin, Y. Yin, H. Zhang, C. Cai, Electrochim. Acta 2010, 558, 8606.

[60] Z. Luo, L. Yuwen, Y. Han, J. Tian, X. Zhu, L. Weng, L. Wang Biosens. Bioelectron. 2012, 36, 179.
[61] L. Wang, X. Lu, Y. Ye, L. Sub, Y. Song, Electrochim. Acta, 2013, 114,484

[62] L. Wang, Y. Zheng, X. Lu, Z. Li, Y. Ye, L. Sub, Y. Song, Sens. Actuators B 2014, 195, 1.

[63] J. Y. Sun, K. J. Huang, Y. Fan, Z.-W. Wu, D. D. Li, Microchim. Acta 2011, 174, 289.

[64] Y. Zhou, H. Yang, H. Y. Chen, H. Y. Chen, Talanta 2008, $76,419$.

[65] W. Chen, Y. Ding, J. Akhigbe, C. Brückner, C. M. Li, Y. Lei, Biosens. Bioelectron. 2010, 26, 504.

[66] C. Deng, J. Chen, X. Chen, C. Xiao, L. Ni, S. Yao, Biosens. Bioelectron. 2008, 23, 1272.

[67] B. C. Janegitz, R. Pauliukaite, M. E. Ghica, C. M. A. Brett, O. Fatibello-Filho, Sens. Actuators B 2011, 158, 411.

[68] J. Li, Z. Yang, Y. Tang, Y. Zhang, X. Hu, Biosens. Bioelectron. 2013, 41, 698.

[69] Y. Li, F. Wang, F. Huang, Y. Li, S. Feng, J. Electroanal. Chem. 2012, 685, 86 .

[70] X. Liu, L. Shi, W. Niu, H. Li, G. Xu, Biosens. Bioelectron. 2008, 23, 1887.

[71] A. J. Bard, L. R. Faulkner, Electrochemical Methods, Wiley, New York, 2001, p. 471.

[72] H. Yu, X. Jian, J. Jin, X. C. Zheng, R. T. Liu, G. C. Ci, Microchim. Acta 2014, DOI 10.1007/s00604-014-1310-x, in press.

[73] X. Kang, Z. Mai, X. Zou, P. Cai, J. Mo Anal. Biochem. 2007, 363, 143 .

Received: August 8, 2014

Accepted: October 30, 2014 Published online: December 14, 2014 